\title{
ЭПИДЕМИОЛОГИЧЕСКИЕ ДЕТЕРМИНАНТЫ РАЗВИТИЯ ДЕПРЕССИВНОГО СИНДРОМА У ЛИЦ, ЗЛОУПОТРЕБЛЯЮЩИХ НАРКОТИЧЕСКИМИ ВЕЩЕСТВАМИ
}

\begin{abstract}
Аннотация. В статье представлены клинические особенности течения депрессивного афбекта у больных, злоупотребляющих психоактивными и наркотическими веществами, определены степени влияния анамнестического бактора на развитие и течение депрессивного синдрома у данной категории людей, проведена оиенка соииального статуса больных с депрессивными расстройствами и с лекарственной зависимостью, установлень особенности психосоматического и психологического статуса данной категории пациентов.

Ключевые слова: психиатрия, депрессивный аффект, лекарственная зависимость, злоупотребление, наркотические вещества, психический статус, психосоматический статус, социальный бактор, семейный анамнез, психоактивные вещества.
\end{abstract}

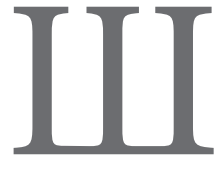

ирокое распространение психической патологии в популяции происходит в основном за счет прогрессивного роста непсихотической психической патологии в виде депрессивных и дистимических расстройств, тревожных и фобических нарушений, стрессовых проявлений разного уровня, личностных декомпенсаций ${ }^{1}$. Неслучайно проблемы психического здоровья становятся предметом специального рассмотрения межгосударственных и международных организаций ${ }^{2}$.

Депрессия - одна из наиболее частых форм психической патологии, выявляемой у больных соматическими и неврологическими заболеваниями. В первичной медицинской практике средние показатели распространенности клинически выраженных депрессий составляют 1,6-8,9\% и близки к популяционным значениям (4-7\%), тогда как при коморбидности аффективного расстройства с неблагоприятно про-

\footnotetext{
Семичов С.Б. Предболезненные психические расстройства. Л.: Медицина, 1987. 187 с.

2 Global Burden of Disease and Risk Factors / LopezA.D., Mathers C.D., Ezzati M. et al. Wash (DC):World Bank; 2006 // http: // www. ncbi. nlm. nih. gov /books /NBK11820; World mental health. Problems and priorities in low-income countries / Desjarlais R., Eisenberg L., Good B. et al. N.Y.: Oxford University Press, 1995 // http://www.ncbi.nlm.nih.gov/pmc/articles/PMC1380710/.
}

текающим соматическим заболеванием значение этого показателя повышается до 14,3-24\%. В результате развернутых и обширных исследований, проведенных как в России, так и в Европе, сделаны попытки разграничить и определить круг основных факторов, ассоциированных с высокой частотой депрессии в общей соматической практике. Среди них такие, как женский пол, пожилой возраст, наличие психотравмирующих ситуаций, потеря семьи (развод, вдовство), работы, низкий доход, а также предшествующая терапия растительными препаратами седативного действия, транквилизаторами, антидепрессантами, нейролептиками ${ }^{3}$. Следует отметить, что существуют определенные противоречия в описаниях корреляций депрессивных состояний с полом, возрастом, социальным положением и многими другими факторами ${ }^{4}$ Принято считать,

\footnotetext{
Воробьева О.В. Клинические особенности депрессии в общемедицинской практике (по результатам программы "КОМПАС") / О.В. Воробьева // Consilium medicum. 2004. № 6(2). [Эл. pecypc - http://old.consilium-medicum.com/media/consilium/04 02/154.shtml]; 12-Month comorbidity patterns and associated factors in Europe: results from the European Study of the Epidemiology of Mental Disorders (ESEMeD) project / Alonso J., Angermeyer M.C., Bernert S. et al // Acta Psychiatr. Scand. 2004. V. 109(420). P. 28-37.

4 Bebbington P. Marital status and depression: A study of English national admission Slatistics / P. Bebbington // Acta psychiatr. Scand. 1987. V. 75(6). P. 640-650; Blecker C.V.R. Depressive
} 


\section{Депрессия и тело}

что эти факторы значительно повышают риск развития депрессий. Большинство из них сами по себе могут выступать в качестве «депрессогенных» у любого человека. Несмотря на то, что эпидемиологическое изучение депрессивных расстройств продвинулось далеко, тем не менее, практически не встречаются работы, в которых были бы рассмотрены особенности клинического течения депрессий у людей, злоупотребляющих наркотическими и психоактивными веществами, взаимовлияния депрессивного аффекта на употребление психоактивных веществ и формирования зависимости от них, не проанализированы факторы и условия, которые способствуют появления психосоматической коморбидности наряду с депрессий у данной категории пациентов, не установлены психологические и психиатрические особенности данных пациентов в связи с вышеназванной коморбидностью.

Таким образом, целью работы стало изучение особенностей клинического течения депрессивного аффекта у больных, злоупотребляющих психоактивными и наркотическими веществами, степени влияния анамнестического фактора на развитие и течение депрессивного синдрома у данной категории людей, оценка факторов социальной среды для больных с депрессивными расстройствами одновременно с лекарственной зависимостью, особенностей психосоматического и психологического статуса на момент первичного обследования.

\section{Материаль и методы исследования}

Нами обследовано 308 больных основной и 36 больных контрольной группы. Нозологическая квалификация расстройств основывалась на классификации психических болезней МКБ-10 с использованием рубрик F-33.00-F-33.01, F-33.10-F-33.11, F-11.2, F-12.2, F-15.2. В основную группу вошли больные в возрасте от 18 до 45 лет (средний возраст $-31,1 \pm 7,46,308$ чел.), в контрольную - от 18 до 50 лет (средний возраст

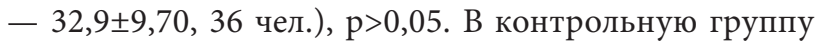
(36 чел.) были включены пациенты с наркотической зависимостью, у которых на момент первичного обследования не наблюдалось признаков депрессивных расстройств и соматических нарушений. Из них, коду F-11.2 (опиомания) соответствовало 10 чел. (27,8\%),

Disorder in Primary Care / C.V.R. Blecker, A.W. Daze // Brit. J. Psychiatr. 1987. V. 150. P. 737-751; Dovess V. Urban-Rural comparisons of depressive disorders in French Canada / Dovess V., Murfy H.B.M., Tousignant M. // J. Nerv. Ment. Dis. 1987. Vol. 157 (8). P. 457-465; Weissman M.M. Affective disorders in a US Urban Community / Weissman M.M., Myers J.K. // Arch. Gen. Psychiatry. 1978. Vol. 35. P. 1304-1311. коду F-12.2 (каннабизм) - 16 чел. (44,4\%), F-15.2 (эфедромания) -10 чел. $(27,8 \%)^{5}$. В основную группу (308 человек) включались пациенты, употреблявшие психоактивные вещества, а также имеющие аффективные расстройства (F-33.00, F-33.10), в том числе при наличии соматических симптомов на фоне депрессии (238 чел. - F-33.01, F-33.11)

Всем пациентам основной (308 человек) и контрольной (36 человек) групп проводилось обследование, которое включало скрининговый опрос с заполнением специальной карты, разработанной для данной работы, а также клинико-психопатологическое, клинико-психометрическое, клинико-психологическое исследование.

Для проведения динамической оценки психического состояния использовалась специально разработанная «Карта оценки психотравмирующих ситуаций и психопатологической структуры расстройств тревожно-депрессивного спектра» ${ }^{7}$. Для определения типа личностной аффективности использовалась методика измерения уровня макиавеллизма личности (МАК-ШКАЛА) ${ }^{8}$ и методика «Семантический дифференциал» ${ }^{9}$. С целью анализа способности к социальной адаптации применялись тесты Ли́ри ${ }^{10}$. С целью анализа характера психотравмирующих ситуаций, выраженности депрессивных и психосоматических расстройств использовались: опросник выраженности психопатологической симптоматики (Symptom check list-90-revised - SCL-90-R) ${ }^{11}$, определение индекса

5 МКБ-10: Психические расстройства и расстройства поведения (на русском языке). Официальный текст МЗ РФ, адаптированный для применения в РФ, разрешенный к копированию и печати [Эл. pecypc - http://www.rusmedserv.com/ psychsex/icd10.shtml].

6 Там же.

7 Клайн Пол. Справочное руководство по конструированию тестов / П. Клайн. М.: ПАН Лтд, 1994. 288 с.

8 Знаков В.В. Макиавеллизм: психологическое свойство личности и методика его исследования / В.В. Знаков // Психологический журнал. 2000. Т. 21. № 5. С. 16-22.

9 Петренко В.Ф. Введение в экспериментальную психосемантику: исследование форм репрезентации в обыденном сознании / В.Ф. Петренко. М.: Изд-во МГУ, 1983. 175 с.; Шмелев А.Г. Введение в экспериментальную психосемантику / А.Г. Шмелев. М.: Изд-во МГУ, 1983. 157 с.; Language, meaning and culture: the selected papers of C.E. Osgood / Ed. by Charles. E. Osgood and Oliver C.S. Tzeng. New York (etc.): Praeger, 1990 XIII. 402 p.

10 Собчик Л.Н. Диагностика межличностных отношений. Практическое руководство к традиционному и компьютерному вариантам теста / Л.Н. Собчик. М.: Боргес, 2010. 52 с.

11 Тарабрина Н.В. Практическое руководство по психологии посттравматического стресса. Ч. 1. Теория и мето- 


\section{Психология и психотехника 6(57) • 2013}

тяжести зависимости ${ }^{12}$ и опросник для выявления признаков вегетативных изменений ${ }^{13}$. Для оценки выраженности тревожно-депрессивных расстройств и уровня переживаемого стресса использовались «Шкала восприятия стресса PSS10» ${ }^{14}$, опросник «Тип отношения к болезни» (ЛОБИ) $)^{15}$, методика диагностики самооценки $^{16}$, шкала самооценки Дембо-Рубинштейн ${ }^{17}$. Для определения типа аффективности использовались проективные методики «Цветовой тест отношений», тесты Маховер ${ }^{18}$.

Для статистического анализа полученных данных использовали программные пакеты «Statistica for Windows 8.0» (Stat Soft inc., США) и SPSS 14. Описание количественных признаков проводилось с использованием параметрических методов. Достоверность разницы показателей определяли с помощью t-критерия Стьюдента и F-критерия Фишера. Количественные показатели представлены в виде $\mathrm{M} \pm \mathrm{m}$, где $\mathrm{M}$ - среднее, $\mathrm{m}$ стандартное отклонение ${ }^{19}$. Для оценки психометрических показателей и шкал использовался анализ таблиц сопряженности признаков с применением критерия $\chi 2$. За уровень достоверности статистических показателей принято $\mathrm{p}<0,05^{20}$.

ды / Н.В. Тарабрина, В.А. Агарков, Ю.В. Быховец и др. Л.: Когито-Центр, 2007. 208 с.

12 Индекс тяжести зависимости: версия Treatnet: Руководство и опросник. М., Верди, 2009. 128 с.

13 Вейн В.М. Вегетативные расстройства. Клиника, диагностика, лечение / В.М. Вейн. М.: Медицина, 1998. 740 с.

14 Cohen S. A global measure of perceived stress /Cohen S., Kamarck T., Mermelstein R. // J Health and Soc. Behavior. 1983. V. 24. P. $385-396$.

15 Кабанов М.М. Методы психологической диагностики и коррекции в клинике / М.М. Кабанов, А.Е. Личко, В.М. Смирнов. М.: Медицина, 1983.312 с.

16 Психотерапия в общесоматической медицине: Клиническое руководство / Под общ. ред. Б.В. Михайлова. Харьков: Прапор, 2002. 128 с.

17 Яньшин П.В. Клиническая психодиагностика личности: учеб.-метод. пособие / П.В. Яньшин. 2-е изд., испр. СПб.: Речь, 2007. 320 с.

18 Райгородский Д.Я. Практическая психодиагностика. Методики и тесты / Д.Я. Райгородский. Самара: БАХРАХ-М, $2001.672 \mathrm{c}$

19 Реброва О.Ю. Статистический анализ медицинских данных. Применение пакета прикладных программ STATISTICA / О.Ю. Реброва. М.: Медиа-сфера, 2004. 312 с.; Флетчер Р. Клиническая эпидемиология. Основы доказательной медицины / Р. Флетчер, С. Флетчер, Э. Вагнер. М.: Медиа-сфера, 2004. 352 с.

20 Там же.

\section{Результать и обсуждение}

В результате анализа соответствующих картопросников нами показано (табл.1): отсутствие разницы в давности употребления наркотических психотропных веществ: колебание от 1 до 9 лет в основной группе (в среднем - 6,65 44,3 ) и от 1 до 8 лет -

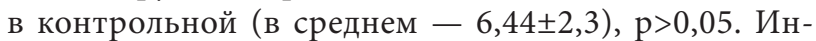

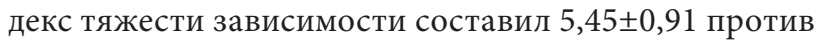
$5,41 \pm 0,87$ баллов, p>0,05 (табл. 1). В основной группе соотношение опиомании, каннабизма и эфедромании представлено как 21,4\% (66 чел.), 42,2\% (130 чел.), 36,4\% (112 чел.). В контрольной группе эти показатели составили 27,8\% (10 чел. - опиомания), 44,4\% (16 чел. каннабизм), 27,8\% (10 чел. - эфедромания), p>0,05. Таким образом, не обнаружено достоверных различий в длительности употребления наркотических веществ, тяжести зависимости между основной и контрольной группами.

Учитывая тот факт, что в основную группу включали пациентов с аффективными расстройствами - длительность депрессивных расстройств в основной группе составила от 1 до 10 лет $(5,35 \pm 2,53$ лет), количество

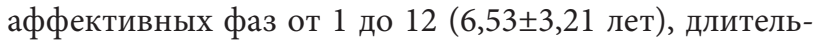
ность депрессивного эпизода до поступления в клинику $28,8 \pm 2,5$ дней. Соматические симптомы диагностированы в течение последних $-2,48 \pm 0,84$ лет.

Таблица 1

Сравнительная характеристика основной и контрольной групп в зависимости возраста, длительности депрессивных, соматических расстройств, наркотической зависимости

\begin{tabular}{|l|c|c|c|}
\hline & $\begin{array}{c}\text { Основная } \\
\text { группа } \\
\mathbf{n = 3 0 8}\end{array}$ & $\begin{array}{c}\text { Контрольная } \\
\text { группа } \\
\mathbf{n = 3 6}\end{array}$ & $\mathbf{p}$ \\
\hline $\begin{array}{l}\text { Анамнез } \\
\text { наркомании }\end{array}$ & $6,65 \pm 4,3$ & $6,44 \pm 2,3$ & $>0,05$ \\
\hline Каннабизм & $130(42,2 \%)$ & $10(27,8 \%)$ & $>0,05$ \\
\hline Эфедромания & $112(36,4 \%)$ & $16(44,4 \%)$ & $>0,05$ \\
\hline Опиомания & $66(21,4 \%)$ & $10(27,8 \%)$ & $>0,05$ \\
\hline
\end{tabular}

При дальнейшем анализе мы определили (см. табл. 2), гендерное распределение не имело достоверных различий между основной и контрольной группами: так, соотношение мужчин составило 60,7\% (181 чел.) и $58,4 \%$ (21 чел.), $\mathrm{p}>0,05$, женщин, соответственно, 39,3\% (127 чел.) против 41, 6\% (15 чел.), p>0,05. 
Таблииа 2

Сравнительная характеристика основной и контрольной групп

в зависимости от пола и индекса массы тела

\begin{tabular}{|c|c|c|c|}
\hline & $\begin{array}{c}\text { Основная } \\
\text { группа } \\
\text { n=308 }\end{array}$ & $\begin{array}{c}\text { Контрольная } \\
\text { группа } \\
\text { n=36 }\end{array}$ & p \\
\hline \multicolumn{4}{|c|}{ Пол } \\
\hline мужской & $181(58,8 \%)$ & $21(58,3 \%)$ & $>0,05$ \\
\hline женский & $127(41,2 \%)$ & $15(41,7 \%)$ & $>0,05$ \\
\hline \multicolumn{4}{|c|}{ Индекс массы тела (кг/м²) } \\
\hline & $24,4 \pm 3,8$ & $18,9 \pm 4,9$ & $<0,05$ \\
\hline
\end{tabular}

В данном блоке проводилось также изучение ряда факторов, которые, возможно, могут быть факторами риска депрессивных и психосоматических расстройств. В частности, индекс массы тела можно отметить как достоверный фактор риска депрессивных расстройств у больных наркотической зависимостью $(24,4 \pm 3,8$ против

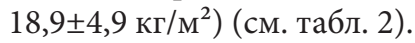

При оценке социального статуса, среди пациентов с депрессивными расстройствами и наркотической зависимостью в качестве фактора риска можно отметить потерю одного или двух родителей в детстве (статус сироты или полусироты) - 19,2 против 2,8\%, $(\mathrm{p}<0,05)$. Указать следует также на такой фактор риска, как семейное положение - среди пациентов, никогда не состоявших в браке количество депрессивных расстройств достоверно больше (46,4 против 19,4\%, $\mathrm{p}<0,05)$, с обратной зависимостью для больных, состоящих в браке $(9,1-$ основная группа, $55,6 \%$ - группа контроля, $\mathrm{p}<0,05)$, (см. табл. 3)

Таблица 3

\section{Сравнительная характеристика основной и контрольной групп в зависимости от социальных анамнестических факторов}

\begin{tabular}{|c|c|c|c|}
\hline & $\begin{array}{c}\text { Основная группа } \\
\text { n=308 }\end{array}$ & $\begin{array}{c}\text { Контрольная группа } \\
\text { n=36 }\end{array}$ & $\mathbf{p}$ \\
\hline \multicolumn{4}{|l|}{ Социальный статус } \\
\hline сирота/полусирота & $59(19,2 \%)$ & $1(2,8 \%)$ & $<0,05$ \\
\hline антисоциальное поведение до ПАВ & $23(7,5 \%)$ & $4(11,1 \%)$ & $<0,05$ \\
\hline безработный & $179(58,1 \%)$ & $20(55,6 \%)$ & $>0,05$ \\
\hline офисный работник & $35(11,4 \%)$ & $3(8,3 \%)$ & $>0,05$ \\
\hline студент & $19(6,2 \%)$ & $2(5,6 \%)$ & $>0,05$ \\
\hline рабочий & $75(24,4 \%)$ & $11(30,6 \%)$ & $>0,05$ \\
\hline \multicolumn{4}{|c|}{ Уровень образования } \\
\hline среднее & $72(23,4 \%)$ & $23(63,9 \%)$ & $<0,05$ \\
\hline специальное (неоконченное) & $50(16,3 \%)$ & $2(5,6 \%)$ & $>0,05$ \\
\hline специальное & $48(15,6 \%)$ & $8(22,2 \%)$ & $>0,05$ \\
\hline незаконченное высшее & $43(14,0 \%)$ & $1(2,8 \%)$ & $>0,05$ \\
\hline высшеe & $95(30,8 \%)$ & $2(5,6 \%)$ & $<0,05$ \\
\hline \multicolumn{4}{|c|}{ Семейное положение } \\
\hline никогда не состоял в браке & $143(46,4 \%)$ & $7(19,4 \%)$ & $<0,05$ \\
\hline разведен & $137(44,5 \%)$ & $9(25,0 \%)$ & $>0,05$ \\
\hline состоит в браке & $28(9,1 \%)$ & $20(55,6 \%)$ & $<0,05$ \\
\hline детей нет & $200(64,9 \%)$ & $18(50,0 \%)$ & $>0,05$ \\
\hline 1 ребенок & $82(26,6 \%)$ & $13(36,1 \%)$ & $>0,05$ \\
\hline 2 и более детей & $26(8,5 \%)$ & $5(13,9 \%)$ & $>0,05$ \\
\hline
\end{tabular}




\section{Психология и психотехника 6(57) • 2013}

Таблииа 4

Влияние семейного анамнеза на депрессивный аффект у пациентов основной и и контрольной групп

\begin{tabular}{|c|c|c|c|}
\hline & $\begin{array}{l}\text { Основная группа } \\
n=308\end{array}$ & $\begin{array}{c}\text { Контрольная группа } \\
n=36\end{array}$ & $\mathbf{p}$ \\
\hline $\begin{array}{l}\text { Возраст родителей при рождении пациента } \\
\text { (до } 18 \text { и после } 35 \text { лет) }\end{array}$ & $85(27,6 \%)$ & $3(8,3 \%)$ & $<0,05$ \\
\hline $\begin{array}{l}\text { Горе (траур) матери из-за смерти до, во время } \\
\text { беременности или после родов близкого человека }\end{array}$ & $140(45,5 \%)$ & $0(0,0 \%)$ & $<0,05$ \\
\hline Наличие аборты и выкидыши у матери & $152(49,4 \%)$ & $5(13,4 \%)$ & $<0,05$ \\
\hline Смерть ребенка до рождения предыдущего & $30(9,7 \%)$ & $1(2,8 \%)$ & $<0,05$ \\
\hline Осложнения беременности у матери & $94(30,5 \%)$ & $7(19,4 \%)$ & $>0,05$ \\
\hline Осложнения в родах & $71(23,1 \%)$ & $8(22,2 \%)$ & $>0,05$ \\
\hline Грудное вскармливание & $139(45,1 \%)$ & $12(33,3 \%)$ & $>0,05$ \\
\hline Детский сад до 18 мес. & $165(53,6 \%)$ & $5(13,4 \%)$ & $<0,05$ \\
\hline Плохие отношения между родителями & $234(75,9 \%)$ & $7(19,4 \%)$ & $<0,05$ \\
\hline Нахождение в зоне военных конфликтов 1 из родителей & $26(8,4 \%)$ & $0(0 \%)$ & $<0,05$ \\
\hline Измена мужа & $196(63,6 \%)$ & $4(11,1 \%)$ & $<0,05$ \\
\hline Развод & $143(46,4 \%)$ & $7(19,4 \%)$ & $<0,05$ \\
\hline Стресс в детстве & $260(84,4 \%)$ & $11(30,6 \%)$ & $<0,05$ \\
\hline Ранние разлуки с матерями & $211(68,5 \%)$ & $8(22 \%)$ & $<0,05$ \\
\hline Желанный ребенок (пациент) & $24(7,8 \%)$ & $5(13,9 \%)$ & $>0,05$ \\
\hline Неопределенное чувство «вины» & $114(37,0 \%)$ & $6(16,7 \%)$ & $<0,05$ \\
\hline Наличие братьев/сестер & $143(46,4 \%)$ & $7(19,4 \%)$ & $<0,05$ \\
\hline \multicolumn{4}{|c|}{ Вредные привычки родителей } \\
\hline Алкоголизм & $43(14,0 \%)$ & $4(11,1 \%)$ & $>0,05$ \\
\hline Курение & $85(27,6 \%)$ & $6(16,7 \%)$ & $>0,05$ \\
\hline Прием наркотических веществ & $7(2,3 \%)$ & $1(2,8 \%)$ & $>0,05$ \\
\hline Посещение ночных клубов родителями & $66(21,4 \%)$ & $4(11,1 \%)$ & $>0,05$ \\
\hline Всего & $160(51,9 \%)$ & $12(33,3 \%)$ & $>0,05$ \\
\hline \multicolumn{4}{|c|}{ Социальный статус родителей } \\
\hline Безработный & $44(14,3 \%)$ & $20(55,6 \%)$ & $<0,05$ \\
\hline Офисный работник & $83(26,9 \%)$ & $11(30,6 \%)$ & $>0,05$ \\
\hline Рабочий & $13(4,2 \%)$ & $1(2,8 \%)$ & $<0,05$ \\
\hline Высокий социальный статус & $159(51,6 \%)$ & $4(11,1 \%)$ & $>0,05$ \\
\hline
\end{tabular}

Место работы и уровень образования пациента до начала заболевания в нашем исследовании также было определены как значимый фактор риска. Так среди пациентов с сопутствующей депрессией доля больных с высшим образованием была приблизительно в 5 раз большей чем у пациентов без сопутствующей депрессии ( $<<0,05)$ (см. табл. 4). Кроме того, среди лиц с высшим образованием, было 35 человек с защищенной научной степенью $(36,8 \%$ от всех лиц имеющих высшее образование). Среди пациентов, не имевших детей, был определен как высокий уровень наркотической зависимости (в контрольной группе 50,0\%); депрессивные расстройства встречались несколько чаще $(64,9 \%)$, чем при наличии 1-го (26,6\% против $36,1 \%)$.
Антисоциальное поведение до начала приема психоактивных веществ наблюдалось чаще у пациентов без депрессивных расстройств - 11,1\% против 7,5\% основной группы, $\mathrm{p}<0,05$.

При анализе особенностей отношений между родителями больного, семейного анамнеза, некоторых фактов из раннего детства было установлено следующее (табл. 4). У больных основной группы достоверным фактором риска аффективных расстройств можно считать возраст родителей меньше 18 и более 35 на момент рождения ребенка $(27,6$ против $8,3 \%, \mathrm{p}<0,05)$, наличие аффективных расстройств у матери (11,0 против $0,0 \%$, $\mathrm{p}<0,05)$. Среди пациентов основной группы посещать 
Депрессия и тело

Puc. 1

\section{Распределение типа ведущего аффекта в группе больных с депрессивными расстройствами и наркотической зависимостью}

\section{Тип аффекта}

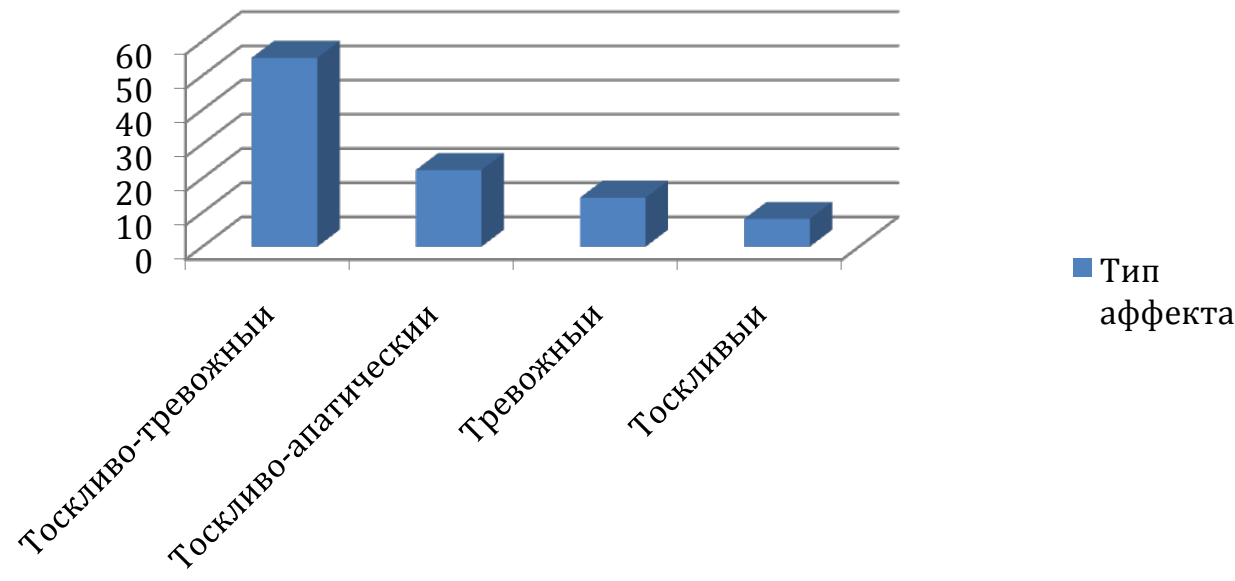

детский сад до 18 месяцев начали 53,6 \% против 13,4 \% контрольной группы ( $<<0,05)$, что также можно считать неблагоприятным фактором для развития депрессии в молодом и среднем возрасте. На «плохие» отношения между родителями (недостаточное общение, отсутствие «любви», «понимания», развод и др.) указало 75,9\% основной группы и только 19,4\% контрольной группы. Из этой же группы большинство «депрессивных» больных указало $(84,4 \%, \mathrm{p}<0,05)$ на пережитый в детстве стресс из-за «разлуки» с одним или двумя родителями, отсутствие контакта, недостаточное понимание, отсутствие «любви», ревность к другим членам семьи. При этом, у 46,4\% пациентов основной группы и 19,4\% больных контрольной группы были братья или сестры (p<0,05). Только 7,8\% обследованных основной группы и 13,9\% контрольной группы считало себя «желанным ребенком» (p>0,05). Из-за разных причин 37,0\% депрессивных пациентов испытывало неопределенное «чувство вины» $(\mathrm{p}<0,05)$.

Весьма определяющими факторами развития депрессии служили следующие: горе (траур) матери из-за смерти до, во время беременности или после родов близкого человека, наличие абортов и выкидышей у матери, смерть ребенка до рождения предыдущего ( $<<0,05$ во всех случаях) (табл. 4). Несомненно, важную роль в развитии депрессивного аффекта у лиц с наркотической зависимостью играли такие анамнестические факторы как нахождение в зоне военных конфликтов одного из родителей, наличие измены мужа, развод, стресс в детстве, ранние разлуки детей с матерями (р<0,05 во всех случаях).(табл. 4).
Вредные привычки у родителей чаще встречались среди депрессивных пациентов (алкоголизм - 14,0 против $11,1 \%$, курение - 27,6 против 16,7\%, прием наркотических веществ - 2,3 против 2,8\%, посещение ночных клубов - 21,4 против 11,1\%, p>0,05). При анализе социального статуса родителей, в группе больных с наркотической зависимостью без депрессии чаще встречались безработные 55,6\% (p<0,05), у «депрессивных» больных на фоне наркотической зависимости родители чаще имели высокий социальный статус 51,6\% против $11,1 \%, \mathrm{p}<0,05$.

По типу ведущего аффекта преобладали больные с тоскливо-тревожным аффектом - 55,2\% (170 чел.), далее - тоскливо-апатическим (22,4\%, 69 чел.), затем по частоте следовал тревожный аффект (14,3\%, 44 чел.), с наименьшей встречаемостью тоскливого типа $(8,1 \%$, 25 чел.), (рис. 1).

Из симптомокомплекса психических нарушений у депрессивных пациентов достоверно преобладали ипохондрия $(78,9$ против $8,3 \%, \mathrm{p}<0,05)$, тревожность (91,9 против $11,1 \%, \mathrm{p}<0,05)$, фобия $(94,1$ против $11,1 \%$, $\mathrm{p}<0,05)$, сверхценные идеи (45,5 против $22,2 \%, \mathrm{p}<0,05)$, с недостоверным распределением агрессии (53,6 против $58,3 \%)$ и застенчивости (52,6 против $38,9 \%)$, ( табл. 5).

Частота астенического синдрома в основной группе была достоверно выше, чем в контрольной (88,3 против $16,7 \%, \mathrm{p}<0,05)$. Индекс астении по шкале астенического 


\section{Психология и психотехника 6(57) • 2013}

Таблииа 5

Психический симптомокомплекс и типы психосоматических расстройств у пациентов основной и контрольной групп

\begin{tabular}{|l|c|c|c|}
\hline & $\begin{array}{c}\text { Основная группа } \\
\mathbf{n = 3 0 8}\end{array}$ & $\begin{array}{c}\text { Контрольная группа } \\
\mathbf{n = 3 6}\end{array}$ & $\mathbf{p}$ \\
\hline Психический симптомокомплекс & $<0,05$ \\
\hline ипохондрия & $246(78,9 \%)$ & $3(8,3 \%)$ & $<0,05$ \\
\hline тревожность & $283(91,9 \%)$ & $4(11,1 \%)$ & $<0,05$ \\
\hline фобия & $290(94,1 \%)$ & $4(11,1 \%)$ & $<0,05$ \\
\hline сверхценные идеи & $140(45,5 \%)$ & $8(22,2 \%)$ & $>0,05$ \\
\hline агрессия & $165(53,6 \%)$ & $21(58,3 \%)$ & $>0,05$ \\
\hline застенчивость & $162(52,6 \%)$ & $14(38,9 \%)$ & \\
\hline & \multicolumn{2}{|c|}{ Астенический синдром } & $<0,05$ \\
\hline частота & $275(88,3 \%)$ & $6(16,7 \%)$ & $<0,05$ \\
\hline выраженность & $92,2 \pm 18,2$ & $79,1 \pm 5,23$ & \\
\hline & Tип психосоматического расстройства & $<0,05$ \\
\hline классическое соматическое & $112(36,4 \%)$ & $0(0,0 \%)$ & $<0,05$ \\
\hline гипохондрическое & $62(20,1 \%)$ & $0(0,0 \%)$ & $<0,05$ \\
\hline соматоформное & $64(20,8 \%)$ & $0(0,0 \%)$ & \\
\hline вегетативное & & & \\
\hline
\end{tabular}

состояния ${ }^{21}$ в основной группе превышал таковой в контрольной группе и составил $92,2 \pm 18,2$ против $79,1 \pm 5,23$ баллов, (р<0,05), (табл. 5).

Таким образом, в основной группе было определено 238 пациентов с наличием психосоматических расстройств, из них классическое соматическое расстройство установлено у 112 чел. (36,4\%), гипохондрическое - у $62(20,1 \%)$, соматоформное вегетативное - у 64 (20,8\%) человек (табл. 5).

При оценке психологических особенностей, следует отметить достоверные различия поведенческого паттерна (тест Айзенка) между основной и контрольной группами ( $<0,05)$, отсутствие достоверных различий при распределении типов темперамента (табл. 6). Исходя из данных теста Лири и анализа межличностных отношений, у больных с аффективными расстройствами и наркотической зависимостью преобладали эгоистичный $(22,7$ против $5,6 \%, \mathrm{p}<0,05)$ и подозрительный $(22,7$ против $2,8 \%, \mathrm{p}<0,05)$ типы отношений, а при наркотической зависимости без аффективных расстройств подчиняемый $(47,2$ против $9,1 \%, \mathrm{p}<0,05)$ и зависимый (33,3 против $11,4 \%, \mathrm{p}<0,05)$ типы (табл. 6).

21 Майкова Л.Д. Настольная книга практического психолога: учеб. пособие: в 2 кн. / Л.Д. Майкова, Т.Г. Чертова, Е.И. Рогов. 2-е изд., перераб. и доп. М.: Гуманит. изд. центр ВЛАДОС, 1999. Кн. 1. 384 с.
При оценке отношения к болезни (опросник ЛОБИ) достоверные различия среди больных основной группы можно установлены ипохондрического $(24,0 \%, \mathrm{p}<0,05)$, меланхолического $(27,9 \%, \mathrm{p}<0,05)$ и эгоцентрического $(21,1 \%, \mathrm{p}<0,05)$ типов, среди контрольной группы - для апатического $(33,3 \%, \mathrm{p}<0,05)$, сенситивного $(25,0 \%, \mathrm{p}<0,05)$, неврастенического типов $(27,8 \%, \mathrm{p}<0,05)$.

На основании данных характеристик групп больных можно сделать следующие выводы:

1) Наличие депрессивного аффекта значительно изменяет картину течения зависимости от психоактивных и наркотических веществ.

2) Наиболее встречаемой формой депрессивного аффекта у людей, злоупотребляющих наркотическими веществами является тоскливо-тревожный тип, который сопровождается, преимущественно, ипохондрическими, тревожными, фобическими симптомокомплексами, а также комплексом наличия сверхценных идей.

3) У абсолютного большинства наркозависимых с депрессией в отличии от аналогичной группы людей без депрессивного аффекта, наблюдается астенический синдром с тяжелой степенью его выраженности.

4) Психологическими особенностями данной когорты пациентов является преобладание интровертного поведенческого паттерна над экстравертным, эгоистичного, подчиняемого или зависимого типа межличност- 


\section{Характеристика психологических особенностей основной и контрольной групп при депрессивных расстройствах и наркотической зависимости}

\begin{tabular}{|c|c|c|c|}
\hline & $\begin{array}{c}\text { Основная группа } \\
n=308\end{array}$ & $\begin{array}{c}\text { Контрольная группа } \\
\text { n=36 }\end{array}$ & p \\
\hline \multicolumn{4}{|c|}{ Тест Айзенка (поведенческий паттерн) } \\
\hline Интраверт & $162(52,6 \%)$ & $9(25,0 \%)$ & $<0,05$ \\
\hline Экстраверт & $146(47,4 \%)$ & $27(75,0 \%)$ & $<0,05$ \\
\hline \multicolumn{4}{|c|}{ Tип темперамента } \\
\hline Меланхолический & $215(69,8 \%)$ & $22(61,1 \%)$ & $>0,05$ \\
\hline Сангвинический & $13(4,2 \%)$ & $3(8,3 \%)$ & $>0,05$ \\
\hline Холерический & $58(18,8 \%)$ & $8(22,2 \%)$ & $>0,05$ \\
\hline Флегматический & $22(7,1 \%)$ & $3(8,3 \%)$ & $>0,05$ \\
\hline \multicolumn{4}{|c|}{ Тип межличностных отношений по Лири } \\
\hline Эгоистичный & $70(22,7 \%)$ & $2(5,6 \%)$ & $<0,05$ \\
\hline Агрессивный & $57(18,5 \%)$ & $2(5,6 \%)$ & $>0,05$ \\
\hline Авторитарный & $48(15,6 \%)$ & $2(5,6 \%)$ & $>0,05$ \\
\hline Подозрительный & $70(22,7 \%)$ & $1(2,8 \%)$ & $<0,05$ \\
\hline Подчиняемый & $28(9,1 \%)$ & $17(47,2 \%)$ & $<0,05$ \\
\hline Зависимый & $35(11,4 \%)$ & $12(33,3 \%)$ & $<0,05$ \\
\hline \multicolumn{4}{|c|}{ Тип отношения к болезни } \\
\hline Ипохондрический & $74(24,0 \%)$ & $0(0,0 \%)$ & $<0,05$ \\
\hline Меланхолический & $86(27,9 \%)$ & $0(0,0 \%)$ & $<0,05$ \\
\hline Апатический & $38(12,3 \%)$ & $12(33,3 \%)$ & $<0,05$ \\
\hline Сенситивный & $11(3,6 \%)$ & $9(25,0 \%)$ & $<0,05$ \\
\hline Эгоцентрический & $65(21,1 \%)$ & $0(0,0 \%)$ & $<0,05$ \\
\hline Анозогнозический & $9(2,9 \%)$ & $0(0,0 \%)$ & $>0,05$ \\
\hline Паранояльный & $25(8,1 \%)$ & $5(13,9 \%)$ & $>0,05$ \\
\hline Неврастенический & $0(0,0 \%)$ & $10(27,8 \%)$ & $<0,05$ \\
\hline
\end{tabular}

ных отношений, ипохондрического, меланхолического, апатического, сенситивного и эгоцентрического отношения к своему состоянию, с абсолютным перевесом меланхолического и апатического типа внутри своей категории.

5) У абсолютного большинства больных с депрессией установлена также психосоматическая коморбидность с преобладанием признаков классического соматического расстройства, которое, в свою очередь, сопровождается увеличенным индексом массы тела.

6) Высокий социальный статус, наличие высшего образования, отсутствие семейного статуса также влияют на наличие депрессивного аффекта у больных злоупотребляющих наркотическими веществами.

7) Основополагающими факторами развития депрессий у наркозависимых являются следующие анамнестические параметры: горе (траур) матери из-за смерти до, во время беременности или после родов близкого человека, наличие абортов и выкидышей у матери, смерть ребенка до рождения предыдущего, нахождение в зоне военных конфликтов одного из родителей, наличие измены мужа, разводы родителей.

8) Нами доказано влияние анамнестического фактора, а именно возраста родителей при рождении ребенка, наличие депрессий у матерей, раннее «отдавание» в детский сад и ранние разлуки с детьми, неадекватные отношения между родителями и стрессы детском возрасте, высокий социальный статус родителей, но не наличия вредных привычек у родителей, на протекание депрессий у лиц, злоупотребляющих психоактивными веществами. 


\section{Психология и психотехника 6(57) • 2013}

\section{Список литературь:}

1. Вейн В.М. Вегетативные расстройства. Клиника, диагностика, лечение / В.М. Вейн. М.: Медицина, 1998. 740 с.

2. Воробьева О.В. Клинические особенности депрессии в общемедицинской практике (по результатам программы “КОМПАС”) / О.В. Воробьева // Consilium medicum. 2004. № 6 (2). [Эл. pecypc - http://old.consilium-medicum. com/media/consilium/04_02/154.shtml].

3. Знаков В.В. Макиавеллизм: психологическое свойство личности и методика его исследования / В.В. Знаков // Психологический журнал. 2000. Т. 21. № 5. С. 16-22.

4. Индекс тяжести зависимости: версия Treatnet: Руководство и опросник. М.: Верди, 2009. 128 с.

5. Кабанов М.М. Методы психологической диагностики и коррекции в клинике / М.М. Кабанов, А.Е. Личко, В.М. Смирнов. М.: Медицина, 1983. 312 с. ил.

6. Клайн Пол. Справочное руководство по конструированию тестов / П. Клайн. М.: ПАН Лтд, 1994. 288 с.

7. Майкова Л.Д. Настольная книга практического психолога: учеб. пособие: в 2 кн. / Л.Д. Майкова, Т.Г. Чертова, Е.И. Рогов. 2-е изд., перераб. и доп. М.: Гуманит. изд. центр ВЛАДОС, 1999. Кн. 1. 384 с. ил.

8. МКБ-10: Психические расстройства и расстройства поведения (на русском языке). Официальный текст М3 РФ, адаптированный для применения в РФ, разрешенный к копированию и печати [Эл. pecypc - http://www. rusmedserv.com/psychsex/icd10.shtml].

9. Петренко В.Ф. Введение в экспериментальную психосемантику: исследование форм репрезентации в обыденном сознании / В.Ф. Петренко. М.: Изд-во МГУ, 1983. 175 с.

10. Психотерапия в общесоматической медицине: Клиническое руководство / под общ. ред. Б.В. Михайлова. Харьков: Прапор, 2002. 128 с.

11. Райгородский Д.Я. Практическая психодиагностика. Методики и тесты / Д.Я. Райгородский. Самара: БАХРAX-M, 2001. $672 \mathrm{c}$.

12. Реброва О.Ю. Статистический анализ медицинских данных. Применение пакета прикладных программ STATISTICA / О.Ю. Реброва. М.: Медиа-сфера, 2004. 312 с.

13. Семичов С.Б. Предболезненные психические расстройства / С.Б. Семичов. Л.: Медицина, 1987. 187 с.

14. Собчик Л.Н. Диагностика межличностных отношений. Практическое руководство к традиционному и компьютерному вариантам теста / Л.Н. Собчик. М.: Боргес, 2010. 52 с.

15. Тарабрина Н.В. Практическое руководство по психологии посттравматического стресса. Ч. 1. Теория и методы / Н.В. Тарабрина, В.А. Агарков, Ю.В. Быховец и др. Л.: Когито-Центр, 2007. 208 с.

16. Флетчер Р. Клиническая эпидемиология. Основы доказательной медицины / Р. Флетчер, С. Флетчер, Э. Вагнер. М.: Медиа-сфера, 2004. 352 с.

17. Шмелев А.Г. Введение в экспериментальную психосемантику / А.Г. Шмелев. М.: Изд-во МГУ, 1983. 157 с.

18. Яньшин П.В. Клиническая психодиагностика личности: учеб.-метод. пособие / П.В. Яньшин. 2-е изд., испр. СПб.: Речь, 2007. 320 с.

19. 12-Month comorbidity patterns and associated factors in Europe: results from the European Study of the Epidemiology of Mental Disorders (ESEMeD) project / Alonso J., Angermeyer M.C., Bernert S. et al. // Acta Psychiatr. Scand. 2004. V. 109(420). P. 28-37.

20. Bebbington P. Marital status and depression: A study of English national admission Slatistics / P. Bebbington // Acta psychiatr. Scand. 1987. V. 75(6). P. 640-650.

21. Blecker C.V.R. Depressive Disorder in Primary Care / C.V.R. Blecker, A.W. Daze // Brit. J. Psychiatr. 1987. V. 150. P. 737-751.

22. Cohen S. A global measure of perceived stress / Cohen S., Kamarck T., Mermelstein R. // J Health and Soc. Behavior. 1983. V. 24. P. 385-396.

23. Dovess V. Urban-Rural comparisons of depressive disorders in French Canada / Dovess V., Murfy H.B.M., Tousignant M. // J. Nerv. Ment. Dis. 1987. Vol. 157 (8). P. 457-465.

24. Global Burden of Disease and Risk Factors / Lopez A.D., Mathers C.D., Ezzati M. et al. Wash (DC):World Bank; 2006. [http: // www. ncbi. nlm. nih. gov /books /NBK11820/].

25. Language, meaning and culture: the selected papers of C. E. Osgood / Ed. by Charles. E. Osgood and Oliver C.S. Tzeng. New York (etc.): Praeger, 1990 XIII. 402 p.

26. Weissman M.M. Affective disorders in a US Urban Community / Weissman M.M., Myers J.K. // Arch. Gen. Psychiatry. 1978. Vol. 35. P. 1304-1311.

27. World mental health. Problems and priorities in low-income countries / Desjarlais R., Eisenberg L., Good B. et al. N.Y.: Oxford University Press, 1995. [http://www.ncbi.nlm.nih.gov/pmc/articles/PMC1380710/]. 


\section{Депрессия и тело}

\section{References (transliteration):}

1. Veyn V.M. Vegetativnye rasstroystva. Klinika, diagnostika, lechenie / V.M. Veyn. M.: Meditsina, 1998. 740 s.

2. Vorob’eva O.V. Klinicheskie osobennosti depressii v obshchemeditsinskoy praktike (po rezul'tatam programmy "KOMPAS”) / O.V. Vorob’eva // Consilium medicum. 2004. № 6 (2). [El. resurs - http://old.consilium-medicum.com/media/ consilium/04_02/154.shtml].

3. Znakov V.V. Makiavellizm: psikhologicheskoe svoystvo lichnosti i metodika ego issledovaniya / V.V. Znakov // Psikhologicheskiy zhurnal. 2000. T. 21. № 5. S. 16-22.

4. Indeks tyazhesti zavisimosti: versiya Treatnet: Rukovodstvo i oprosnik. M.: Verdi, 2009. $128 \mathrm{~s}$.

5. Kabanov M.M. Metody psikhologicheskoy diagnostiki i korrektsii v klinike / M.M. Kabanov, A.E. Lichko, V.M. Smirnov. M.: Meditsina, 1983. 312 s. il.

6. Klayn Pol. Spravochnoe rukovodstvo po konstruirovaniyu testov / P. Klayn. M.: PAN Ltd, 1994. 288 s.

7. Maykova L.D. Nastol'naya kniga prakticheskogo psikhologa: Ucheb. posobie: V 2 kn. / L.D. Maykova, T.G. Chertova, E.I. Rogov. 2-e izd., pererab. i dop. M.: Guma-nit. izd. tsentr VLADOS, 1999. Kn. 1. 384 s: il.

8. MKB-10: Psikhicheskie rasstroystva i rasstroystva povedeniya (na russkom yazyke). Ofitsial'nyy tekst MZ RF, adaptirovannyy dlya primeneniya v RF, razreshennyy k kopirovaniyu i pechati. [El. resurs - http://www.rusmedserv.com/ psychsex/icd10.shtml].

9. Petrenko V.F. Vvedenie v eksperimental'nuyu psikhosemantiku: issledovanie form reprezentatsii v obydennom soznanii / V.F. Petrenko. M.: Izd-vo MGU, 1983. 175 s.

10. Psikhoterapiya $\mathrm{v}$ obshchesomaticheskoy meditsine: Klinicheskoe rukovodstvo / Pod obshch. red. B.V. Mikhaylova. Khar'kov: Prapor, 2002. 128 s.

11. Raygorodskiy D.Ya. Prakticheskaya psikhodiagnostika. Metodiki itesty/ D.Ya. Raygorodskiy. Samara: BAKhRAKh-M, 2001.672 s.

12. Rebrova O.Yu. Statisticheskiy analiz meditsinskikh dannykh. Primenenie paketa prikladnykh programm STATISTICA / O.Yu. Rebrova. M.: Media-sfera, 2004. 312 s.

13. Semichov S.B. Predboleznennye psikhicheskie rasstroystva / S.B. Semichov. L.: Meditsina, 1987. 187 c.

14. Sobchik L.N. Diagnostika mezhlichnostnykh otnosheniy. Prakticheskoe rukovodstvo k traditsionnomu i komp'yuternomu variantam testa / L.N. Sobchik. M.: Borges, 2010. 52 s.

15. Tarabrina N.V. Prakticheskoe rukovodstvo po psikhologii posttravmaticheskogo stressa. Ch. 1. Teoriya i metody / N.V. Tarabrina, V.A. Agarkov, Yu.V. Bykhovets i dr. L.: Kogito-Tsentr, 2007. 208 s.

16. Fletcher R. Klinicheskaya epidemiologiya. Osnovy dokazatel'noy meditsiny / R. Fletcher, S. Fletcher, E. Vagner. M.: Media-sfera, 2004. $352 \mathrm{~s}$.

17. Shmelev A.G. Vvedenie v eksperimental'nuyu psikhosemantiku / A.G. Shmelev. M.: Izd-vo MGU, 1983. 157 s.

18. Yan'shin P.V. Klinicheskaya psikhodiagnostika lichnosti. Uchebno-metodicheskoe posobie / P.V. Yan'shin. 2-e izd., ispr. SPb.: Rech, 2007. 320 s.

19. 12-Month comorbidity patterns and associated factors in Europe: results from the European Study of the Epidemiology of Mental Disorders (ESEMeD) project / Alonso J., Angermeyer M.C., Bernert S. et al. // Acta Psychiatr. Scand. 2004. V. 109(420). P. 28-37.

20. Bebbington P. Marital status and depression: A study of English national admission Slatistics / P. Bebbington // Acta psychiatr. Scand. 1987. V. 75(6). P. 640-650.

21. Blecker C.V.R. Depressive Disorder in Primary Care / C.V.R. Blecker, A.W. Daze // Brit. J. Psychiatr. 1987. V. 150. P. 737-751.

22. Cohen S. A global measure of perceived stress / Cohen S., Kamarck T., Mermelstein R. // J Health and Soc. Behavior. 1983. V. 24. P. 385-396.

23. Dovess V. Urban-Rural comparisons of depressive disorders in French Canada / Dovess V., Murfy H.B.M., Tousignant M. // J. Nerv. Ment. Dis. 1987. Vol. 157 (8). P. 457-465.

24. Global Burden of Disease and Risk Factors / Lopez A.D., Mathers C.D., Ezzati M. et al. Wash (DC):World Bank; 2006. [http: // www. ncbi. nlm. nih. gov /books /NBK11820/].

25. Language, meaning and culture: the selected papers of C. E. Osgood / Ed. by Charles. E. Osgood and Oliver C.S. Tzeng. New York (etc.): Praeger, 1990 XIII. 402 p.

26. Weissman M.M. Affective disorders in a US Urban Community / Weissman M.M., Myers J.K. // Arch. Gen. Psychiatry. 1978. Vol. 35. P. 1304-1311.

27. World mental health. Problems and priorities in low-income countries / Desjarlais R., Eisenberg L., Good B. et al. N.Y.: Oxford University Press, 1995. [http://www.ncbi.nlm.nih.gov/pmc/articles/PMC1380710/]. 